\title{
Incidence and Estimation of Socioeconomic Costs Associated with Falls among Elderly in Rural Areas of Korea
}

\author{
Sang Gon Lee \\ Department of Emergency Medical Technology, Daewon University College
}

\begin{abstract}
This study was done to delineate the incidence and the socioeconomic cost associated with fall-re lated inju ries in the rural elderly population. From February 1, 2010 to March 31, 2010, a questionnaire-based interview survey was conducted on 2,295 elderly people aged 65-years or older residing in rural communities: one township and one village of Gyoengsangnam-do (province). Of the 2,295 subjects, 735 (32.0\%) had suffered from fall-related injuries during the past year. The direct cost of these injuries was calculated to be 596,466,000 won (56.6\%). The direct costs included medical costs covered by health insurance and those not covered by insurance. The indirect cost was 458,081,000 won (43.4\%). Of the indirect cost, loss of productivity was $274,993,000$ won, health functional foods were $65,531,100$ won, nursing care was $48,755,000$ won and transportation was $43,122,000$ won. The total socioeconomic costs (direct costs + indirect costs) of the study subjects were $1,054,547,000 \mathrm{~W}$ on. When the above-calculated socioeconomic costs for the 2,295 subjects were applied to the $1,067,262$ Korean rural elderly population in 2009 , the socioeconomic costs attributable to fall-related injuries were estimated to be $343,614,988,000$ won.
\end{abstract}

Keywords Fall Injury, Elderly, Socioeconomic Costs, Rural

\section{Introduction and Background}

With the improved quality of national public health and medical care in accordance with the recent spectacular economic development, the elderly population has been increasing sharply, and Korea's elderly population surpassed $7.1 \%$ of the total population in the year 2000 , thereby making Korea an aging society; by 2022 , the elderly population is being forecast to be over $15.0 \%$ of the total population, and Korea will have become an aged society[1].Falls occurring among the elderly, which are one of the societal problems that manifest as the aging of the population progresses, are a major cause of accidental deaths among the group of elderly aged 65-years or older, Even in cases of minor falls, they can cause serious harm in the forms of phenomena of decrepitude such as hindrance to daily life etc. In examining the incidence of falls among the elderly in Korea, every year about $20 \%$ of the elderly residing in regional areas and about $30 \%$ of the elderly residing in nursing homes are found to suffer from falls[2]. While the consequences of falls can be fatal, the often-occurring physical injuries due to falls are

* Corresponding author:

sang8282@mail.daewon.ac.kr (Sang Gon Lee)

Published online at http://journal.sapub.org/phr

Copyright (C) 2012 Scientific \& Academic Publishing. All Rights Reserved mainly in the hip, waist, wrist, and femur, and about $80-90 \%$ of hip injuries can be attributed to falls[3]. When the loss of ability to walk occurs, one's mobility is decreased and the resulting reduction in ability to lead an independent life can not only be a major cause for admission to nursing homes for the elderly, but can also lead to death due to accompanying complications from fracture surgery and subsequent inability of movement[4]. As described, for an elderly person, a fall can be a serious health threat and the effects of a fall can affect more than just the individual. The long-term stays in hospitals or medical institutions for that elderly person can cause not only a rise in medical expenses but also an increase in psychological, physical, and economical burdens, whereby bringing about social issues that can cause serious familial problems; it is expected that the social and economic costs related to falls among the elderly will steadily grow[5]. A lthough there have been domestic studies on falls a mong the elderly, these studies mostly examined only the risk factors of falls and, as such, finding studies that investigated the economic loss, familial burden, and social burdens is difficult [6-14]. In addition, there are a small number of existing domestic studies on the estimation of socio -economic costs associated with accidents and illnesses; however, there has hardly been any research conducted on socio-economic costs attributable to falls among the elderly. As such, we attempted to present basic materials for the establishment 
and evaluation of prevention policies for injuries sustained by the elderly through estimating the social and economic costs attributable to falls among the elderly.

\section{Search Strategies}

\subsection{Study Subjects}

A census survey was conducted on the study subjects of 2,628 elderly people aged 65-years or older residing in Gyeongsangnam-do (province) over as elect township of one county and one village of another county. The selection of this township and village as the study subjects was based on taking into consideration the number of the elderly in each village and township, and the degrees of super-aging of these areas; the village was selected with focus on the accessibility and usability of health care, which were not considered for the township. For the elderly in the study subject regions, research interviewers visited the homes of the elderly and conducted investigations via 1:1 interviews.

\subsection{Study Methods}

The studies were conducted from February 1, 2010 to March31, 2010 by training 25 long-term care workers ( 10 for the township and 15 for the village)from the health care departments of 2 health care clinics by the researchers beforehand on the contents of the questionnaire. The contents of the questionnaire were comprised of a total of 55 questions, including questions regarding the characteristics of the sociology of population, the factors associated with a fall, whether or not hospitalization due to a fall was used, the number of hospitalizations, description and area of injury, number of days of hospitalization, whether or not an operation was performed, outpatient treatment, number of times of outpatient treatment, duration of outpatient treatment, whether or not Oriental medicine treatment was administered and the related treatment cost, whether or not dental care was received and the treatment cost, the transportation cost, nursing care cost, adult diaper cost, accessory product purchase cost, health food purchase cost, care giving by primary family member, visits by visitors, etc.

\subsection{Method of Estimation of Socio-Economic Cost}

The realities of falls among the elderly study subjects and the socio-economic cost of the elderly who used medical care due to falls during the entire year of 2009 were estimated in terms of direct costs and indirect costs. In the survey questionnaire for calculating the insured portion of health care cost, which is a direct cost, the following were examined: whether or not hospitalization was required, the description of injury, duration of hospitalization, whether or not outpatient was visited, the frequency of outpatient visits and duration of outpatient visits. In addition, by identifying the description and the area of injury, the study subjects were classified based on the symbols and categories of injuries of the ICD-10 codes (International Classification of Diseases).
Since the expenditure per admission to the hospital is absolutely necessary in order to calculate the insured portion of the health care cost, the 2009 statistical detain including medical care cost, expenditure, per admission expenditure, etc., with respect to the age category ICD-10 of groups of the elderly aged 65-69 years, 70-74 years and 75-years or older was provided by the Korea Health Insurance Review Agency and was applied in the study. Also, the calculation for the insured portion of the health care cost was conducted, with respect to the subject patients who used hospitalization and outpatient care services, based on each age group and code, as follows.

(Number of days of hospitalization or outpatient visits) $\times$ (per admission expenditure + statutory co-payments of patients)

The uninsured portion of health care cost was calculated by applying $26.3 \%$ of the insured portion of the health care cost for in-hospital patients and $8.9 \%$ for the patients using outpatient services based on the contents of the ' 2005 health insurance co-payment care cost survey conducted by the National Health Insurance Corporation (2006). Additionally, to calculate the drug costs and the Oriental medicine outpatient costs of patients, the '2009 care cost statistical data' from the Korea Health Insurance Review Agency (2010) was used as a reference. For the indirect costs, the nursing care cost, adult diaper cost, transportation cost, health food purchase cost, accessory product purchase cost, and loss of productivity were calculated; and, by using data such as the 2009 nursing care cost from the Caregivers Association of Korea, price information for Korea, the National Statistical Office of Korea, the Korea Ministry of Labor, etc., the costs of each of the items were calculated based on the questionnaire. The direct and indirect costs associated with falls among the elderly in the rural regional communities calculated in this study were used to estimate the socio-economical costs related to fall accidents of the regional community rural elderly by taking into account the 2009 rural elderly population of Korea in terms of the elderly population and gender in accordance with the 16 regional areas and by conversion, after correcting for the elderly fall incidence figures. The data used in this study, due to the fact that it is of one village region and one township region, is problematic in terms of it's ability to represent the entire nationwide rural elderly population in Korea, and the fact that there are many factors that need to be taken into consideration such as regional differences in terms of incidence, economic levels, the make up of age and gender, the distribution and accessibility of medical facilities, etc.; however, due to the reality that it is difficult to consider all these factors and to compensate for them, we attempted to estimate the approximate socio-economical costs of falls among the elderly in rural regions by compensating for only the fall incidence of municipalities and provinces. The socio-economic costs associated with falls among the elderly of some rural regions calculated in this study were applied to estimate the cost for the $1,067,262$ persons in the 2009 rural elderly population in Korea as follows. 


$$
\underset{\mathrm{i}=1}{\mathrm{Cy}}=\Sigma(\mathrm{C} \times \mathrm{Ri} \times \mathrm{Ni})
$$

$\mathrm{Cy}=$ Socio-economic costs associated with falls among elderly

$\Delta \mathrm{i}=1$ (Seoul), $\mathrm{i}=2$ (Busan), $\mathrm{i}=3($ Daegu $),----\mathrm{i}=16$ (Jeju)

$\mathrm{C}=$ Socio-economic costs per elderly person who experienced falls

$\mathrm{Ri}=$ Regional compensated-fall incidence

$\mathrm{Ni}=$ Regional elderly population

\subsection{Analysis Method}

Of the 2,628 persons surveyed using the questionnaire, the data for 2,295 persons $(87.3 \%)$ was used in this study and was analyzed using the SPSS ver. 15.0 (SPSS Inc., Chicago, IL, USA) program. With the use of analysis of the characteristics of the population sociology of the rural community elderly who are the subjects of this study, and by using the aforementioned estimation method for socio-economic costs, the socio-economic costs associated with falls among the elderly of rural regional communities were estimated.

\section{Results}

\subsection{General Characteristics, Fall Incidence and Injury Types}

Of the 2,295 study subjects, there were 810 men (35.3\%) and 1,485 wo men $(64.7 \%)$, and the average age was 74 -years old. Among the elderly subjects, there were 735 persons who responded as having experienced a fallduring the recent year, thereby making the incidence $32.0 \%$. Of the 2,295 study elderly subjects, $12.3 \%$ responded as having had 1 experience of a fall and $19.7 \%$ responded as having had 2 or more experiences of falls. Among those who experienced a fall, the knee was the highest injury area with $31.2 \%$, followed by the foot with $19.6 \%$, the waist with $15.2 \%$, and the wrist with $9.5 \%$. The most frequent in juries sustained at the time of the fall were abrasion wounds with $24.9 \%$, followed by sprains and strains with $24.5 \%$, fractures with $14.1 \%$, and open wounds with $6.0 \%$ (Table 1 ).

Table 1. General Characteristics, Fall Incidence and Injury Types of Study Subjects

\begin{tabular}{cc}
\hline Variables & No. $(\%)$ \\
\hline Sex & \\
Male & $810(35.3)$ \\
Female & $1,485(64.7)$ \\
Age (yr) & \\
$65-69$ & $741(32.3)$ \\
$70-74$ & $607(26.4)$ \\
$75-79$ & $583(25.4)$ \\
$\geq 80$ & $364(15.9)$ \\
Residence period of home $(y r)$ & \\
$1-9$ & $97(4.2)$ \\
$10-19$ & $135(5.9)$ \\
$\geq 20$ & $2,063(89.9)$
\end{tabular}

\begin{tabular}{|c|c|}
\hline \multicolumn{2}{|c|}{ Main means of mobilization } \\
\hline Walking & $191(8.3)$ \\
\hline Bicycle & $80(3.5)$ \\
\hline Private car & $209(9.1)$ \\
\hline Tax & $23(1.0)$ \\
\hline Bus & $1,599(69.7)$ \\
\hline Power tiller & $53(2.3)$ \\
\hline Stick & $66(2.9)$ \\
\hline Crutch & $1(0.0)$ \\
\hline Walker & $18(0.8)$ \\
\hline Wheelchair & $4(0.2)$ \\
\hline Others (motorbike) & $51(2.2)$ \\
\hline \multicolumn{2}{|l|}{ Occupation } \\
\hline Farming & $1,444(62.9)$ \\
\hline No job & $600(26.1)$ \\
\hline Forestry & $4(0.2)$ \\
\hline Fishery & $51(2.2)$ \\
\hline Laborer & $143(6.3)$ \\
\hline Crafts & $43(1.9)$ \\
\hline Others & $10(0.4)$ \\
\hline \multicolumn{2}{|l|}{ Falls experienced } \\
\hline Yes & $735(32.0)$ \\
\hline No & $1,560(68.0)$ \\
\hline \multicolumn{2}{|l|}{ No. of falls } \\
\hline 1 & $283(12.3)$ \\
\hline$\geq 2$ & 452 (19.7) \\
\hline No falls & $1,560(68.0)$ \\
\hline Total & $2,295(100.0)$ \\
\hline \multicolumn{2}{|l|}{ Injury site } \\
\hline Head & $11(1.5)$ \\
\hline Neck & $14(1.9)$ \\
\hline Chest & $13(1.8)$ \\
\hline Back & $112(15.2)$ \\
\hline Shoulder & $35(4.8)$ \\
\hline Elbow & $59(8.0)$ \\
\hline Wrist & $70(9.5)$ \\
\hline Buttock & $48(6.5)$ \\
\hline Knee & $229(31.2)$ \\
\hline Foot & $144(19.6)$ \\
\hline \multicolumn{2}{|l|}{ Injury type } \\
\hline Fracture & $104(14.1)$ \\
\hline Dislocation & $15(2.0)$ \\
\hline Sprain, Strain & $180(24.5)$ \\
\hline Open wound & $44(6.0)$ \\
\hline Internal organs injury & $1(0.1)$ \\
\hline Abrasion wound & $183(24.9)$ \\
\hline No injury & $206(28.0)$ \\
\hline Others & $2(0.3)$ \\
\hline Sub-total & $735(100.0)$ \\
\hline
\end{tabular}

\subsection{Esti mate of Direct Costs due to Falls}

\subsubsection{Insured Portion of Health Care Cost of Hospitalized Patients}

Of the elderly who experienced a fall in the past year, 117 elderly patients were admitted to the hospital and, of these, 113 pers ons were ad mitted once and 4 persons were ad mitted 2 times, which resulted in 121 cases of incurring insured medical care cost. As a result of the calculations for these cases, the total medical care cost of the health insurance cost of the admitted patients was found to be 289,226,077 won and, of this, the insured portion was $219,708,170$ won and statutory co-payment portion was $69,517,907$ won. The total 
number of days of hospitalization was 2,958 days, for which the average per-patient hospitalization cost was $2,390,000$ won and the average number of days of hospitalization per-patient was seen to be 25-days. The highest insured portion of medical care cost in terms of the injury types based on the ICD-10 codes for hospitalized patients was S82 (the lower leg fractures including the ankle), for which the calculated medical care cost was 45,541,564won, based on 24 patients who were hospitalized for 477 days. The total hospitalization cost of the top 5 injury types was $163,039,848$ won, which accounted for $56.4 \%$ of the total hospitalization care cost (Table 2).

\subsubsection{Insured Portion of Health Care Cost of Outpatient Patient}

The number of elderly who used outpatient services due to a fall during the last year was 324 . The total care cost of outpatients was $85,520,648$ won and, of this, the insured portion of the care cost was $62,835,799$ won and the statutory co-payment was $22,684,849$ won. The total nu mber of times the hospital outpatient services were used was 4,503 times and the per person average was 14 times, with the average per person outpatient care cost being 264,000 won. The total outpatient cost of the top 5 injury types based on the ICD- 10 codes for outpatients was $46,675,468$ won, which accounted for $54.6 \%$ of the total outpatient care cost (Table 3 ).

\subsubsection{Expenditure of Drug Costs and Oriental Medicine Outpatient Patient}

The drug cost of the elderly patients who were admitted to the hospital or used outpatient service due to a fall during the last year was calculated. A total of 2,958 days of hospitalization of 121 cases of hospital admission and a total of 4,503 occurrences of outpatient care used by 324 patients were used for the calculation. For the drug cost, the per day convalescence drug expenses of 37,951 won for an elderly patient admitted to the hospital, according to the Korea Health Insurance Review Agency's (2010) '2009 medical care cost statistical table', and the per day convalescence drug expenses of 6,548 won for an outpatient were applied in the calculation. In addition, when purchasing dietary supplements, 247 elderly patients purchased painkillers, whereby spending 3,705,000 won, and the calculated drug cost including this was $145,450,000$ won(Table 4). The number of elderly patients who used Oriental medicine outpatient services due to a fall during the past year was 260 , with a total of 736 medical care treat ments given to them and the per person amount of Oriental med icine treatment was 3 occurrences. Calculation of the insured portion of the care cost for Oriental medicine outpatients was conducted by applying the 16,364 won figure for the per-admission insured portion from the Korea Health Insurance Review Agency's (2010) '2009 medical care cost statistical table,' and the result of the calculation was $12,044,000$ won.

\subsubsection{Calculation of Uninsured Portion of Health Care Cost}

\author{
and the Total Direct Costs
}

The uninsured portion of health care cost of the elderly patients who used medical care due to a fall during the last year was calculated. Based on the '2005 health insurance co-payment care cost survey' conducted by the Korea National Health Insurance Corporation (2006), 26.3\% of the insured portion of health care cost for the inpatients and $8.9 \%$ for the outpatients were applied. The uninsured portion of the care cost for Oriental medicine outpatients was calculated using the questionnaire via the individuals' direct expense cost, and the total was found to be 850,000 won. The uninsured portions of the hospitalization and outpatient costs of the elderly patients of a fall, including their drug cost and direct expense cost for Oriental medicine were 67,930,000 won total. The insured portion of medical care cost of the elderly patients who used medical care due to a fall during the last year was $528,536,000$ won, and adding to this the uninsured portion and direct expense cost of $67,930,000$ makes the total direct cost associated with falls 596,466,000 won; the direct cost per person who experienced a fall was 812,000 won (Table 5).

\subsection{Estimation of Indirect Cost due to Falls}

\subsubsection{Calculations of the Costs of Nursing Care, Transportation, Health Food Purchase, and Accessory Product Purchase}

The nursing care cost of patients who experienced a fall is the nursing care cost spent due to an admission to the hospital, and the cost of a caregiver or, in cases when a guardian provides care, the opportunity cost of the guardian can be considered as a part of the nursing care cost. In this study, the nursing care cost of 722 days (671 counts throughout the day, 29 counts of daytime, 22 counts of night time) of the 29 elderly fall patients who used caregiver services was calculated. According to the Nursing Association of Korea, in 2009 the nursing care cost for a 24-hour period was 70,000 won ( 35,000 won for daytime and 35,000 won for night time); by applying these figures, the calculated total nursing care cost was $48,755,000$ won. The number of the elderly fall patient subjects who used diapers was 13, and they used 260 diapers in total. There are approximately 10 manufactures of adult diapers in Korea and, due to the fact that there were differences in the products found out through a result of verification of diaper prices based on 2009 price information in Korea, the quantities and prices of the 10 adult diaper manufacturers were taken into consideration and the average figures were calculated, which resulted in 312,000 won based on using a per diaper price of 1,200 won. The costs of transportation, health food purchase, and accessory product purchase of the elderly fall patient subjects were calculated. The calculation of the transportation cost was done by using the 'Estimation of socio-economic cost for the develop ment of strategies for the reduction of injuries and harmful consequences in Korea' conducted by the Yonsei University's Health Policy Institute 
Health Promotion Program Support

Group (2009), calculating the transportation cost per incidence of hospital admission and outpatient visits due to fall-related injuries, resulting in a 14,000 won average cost of round-trip transportation in hospital admission cases and 9,200 won in outpatient visitation cases; in applying these figures, the total transportation cost was calculated to be 43,122,000 won. There were 468 elderly subjects who purchased health functional foods, and the cost incurred by these patients was seen to be $65,531,000$ won, where the perperson average cost was 140,000 won. In addition, 106 persons purchased accessory med ical products such as canes, wheelchairs, walkers, electric wheelchairs, etc., for which the purchasers' out-of-pocket expenses were 25,368,000 won and the per person average was 239,000 won.

\subsubsection{Calculation of Loss of Productivity}

The loss of productivity in the cases where the patients who experienced a fall during the past year were admitted to the hospital or used outpatient service, and the loss of productivity of caregivers who gave care and visitors who visited patients were calculated. In order to calcu late the loss of productivity of patients, the 2009 Wage Structure Survey conducted by the Korea Ministry of Labor was applied, and the $11,921,570$ won figure for men aged 65-years or older and 8,007,215 won figure for women were divided by 365 days to obtain per-day wages. The total loss of productivity was $135,553,000$ won based on 117 out of 121 cases of hospitalized patients and 324 outpatients due to fall-related injuries. 104 persons gave care to the subject patients who were admitted to the hospital and, taking into consideration the number of hours spent on their giving care and by separating these hours into an entire day, daytime, and night time, and by applying the cost of caring, the loss of productivity was calculated and found to be 75,100,000 won. Although some studies do not include the cost of visitations when calculating the socio-economic cost due to diseases, in this study, it was included in the analysis due to the fact that costs such as transportation and the cost of time are actually incurred in visitations, and the number of visitors for the subject patients was 114 , resulting in a total of 1,418 patient visitations. Based on the Korea Statistics Office's 2009 social indexes, the average monthly wage of 2,722,000 won for workers was divided by 30 days, thereby arriving at a 90,733 won per day figure; since there was a possibility of overestimation when calculating the productivity loss of visitors, only $50 \%$ of the calculated cost was applied, which resulted in a calcu lated expense of 64,330,000 won. The total cost of the productivity loss of elderly patients who were admitted to the hospital or used outpatient services, the caregivers who gave care to the patients, and the visitors of patients was calculated to be $274,993,000$ won (Table 6).

Table 2. Treatment Amounts of Inpatients according to Injury Types

\begin{tabular}{|c|c|c|c|c|c|c|}
\hline \multirow{2}{*}{$\begin{array}{c}\text { ICD- } \\
10\end{array}$} & \multirow{2}{*}{ Disease Categories } & \multirow{2}{*}{ Case } & \multirow{2}{*}{$\begin{array}{l}\text { Adm. } \\
\text { days }\end{array}$} & \multicolumn{3}{|c|}{ Treatment amount (Won) } \\
\hline & & & & Insurer & Insured & All \\
\hline S0 1 & Head, open wound & 4 & 276 & $21,925,994$ & $7,712,694$ & $29,638,688$ \\
\hline S02 & Fracture, head or face & 1 & 14 & $1,728,328$ & 593,646 & $2,321,974$ \\
\hline S06 & Head, intracranial injury & 1 & 180 & $24,345,900$ & $6,132,289$ & $30,478,189$ \\
\hline $\mathrm{S} 22$ & Fracture: ribs, chest, back & 1 & 18 & $1,155,006$ & 391,432 & $1,546,438$ \\
\hline $\mathrm{S} 23$ & Dislocation, strain, sprain: chest joints & 4 & 73 & $3,332,193$ & $1,147,499$ & $4,479,692$ \\
\hline S31 & Open wound: abdomen, pelvis & 1 & 3 & 396,081 & 117,841 & 513,922 \\
\hline S32 & Fracture, spine and pelvis & 12 & 337 & $21,329,596$ & $7,165,502$ & $28,495,098$ \\
\hline S33 & $\begin{array}{l}\text { Dislocation, strain, sprain: spinal and } \\
\text { pelvic joints }\end{array}$ & 14 & 445 & $20,105,170$ & $6,945,514$ & $27,050,684$ \\
\hline S42 & Fracture, shoulder and arm & 1 & 25 & $2,187,800$ & 686,102 & $2,873,902$ \\
\hline S43 & Dislocation, strain, sprain: arm joints & 2 & 25 & $1,669,400$ & 531,493 & $2,200,893$ \\
\hline S46 & Muscle injury, shoulder & 1 & 10 & $1,209,830$ & 346,821 & $1,556,651$ \\
\hline S5 1 & Open wound, lower arm & 1 & 7 & 566,160 & 173,166 & 739,326 \\
\hline S52 & Fracture, lower arm & 13 & 224 & $22,158,496$ & $6,727,813$ & $28,886,309$ \\
\hline S53 & Dislocation, strain, sprain: elbow joints & 1 & 50 & $3,807,950$ & $1,229,794$ & $5,037,744$ \\
\hline
\end{tabular}




\begin{tabular}{|c|c|c|c|c|c|c|}
\hline S56 & Tendon/muscle injury, lower arm & 2 & 24 & $2,301,744$ & 679,483 & $2,981,227$ \\
\hline S62 & Fracture, wrist and hand & 2 & 29 & $2,422,227$ & 737,088 & $3,159,315$ \\
\hline S70 & Minor injury, buttocks and femur area & 1 & 10 & 576,140 & 193,736 & 769,876 \\
\hline S72 & Fracture, femur & 4 & 178 & $19,154,452$ & $5,778,186$ & $24,932,638$ \\
\hline S76 & Tendon injury, buttocks and femur area & 1 & 40 & $3,030,240$ & 966,792 & $3,997,032$ \\
\hline S81 & Open wound, lower leg & 3 & 20 & $1,449,480$ & 454,010 & $1,903,490$ \\
\hline S82 & Fracture, ankle and lower leg & 24 & 477 & $34,587,764$ & $10,953,800$ & $45,541,564$ \\
\hline S86 & Tendon/muscle injury, lower leg & 5 & 56 & $4,199,509$ & $1,297,112$ & $5,496,621$ \\
\hline S91 & Open wound, ankle and leg & 1 & 40 & $3,076,080$ & 939,747 & $4,015,827$ \\
\hline S92 & Fracture, foot except ankle & 16 & 345 & $20,447,382$ & $6,762,337$ & $27,209,719$ \\
\hline S93 & Dislocation, strain, sprain: ankle area & 5 & 52 & $2,545,248$ & 854,010 & $3,399,258$ \\
\hline & Total & 121 & 2,958 & $219,708,170$ & $69,517,907$ & $289,226,077$ \\
\hline
\end{tabular}

ICD, International Classification Diseases; Won, Korean currency

Table 3. Treatment Amount of Outpatients according to Injury Types

\begin{tabular}{|c|c|c|c|c|c|c|}
\hline \multirow{2}{*}{ ICD-10 } & \multirow{2}{*}{ Disease categories } & \multirow{2}{*}{ Case } & \multirow{2}{*}{$\begin{array}{l}\text { Visit } \\
\text { days }\end{array}$} & \multicolumn{3}{|c|}{ Treatment amount (Won) } \\
\hline & & & & Insurer & Insured & All \\
\hline So0 & Minor injury, head & 2 & 4 & 60,404 & 28,937 & 89,341 \\
\hline S03 & Dislocation, strain, sprain: Skull & 1 & 1 & 14,213 & 5,692 & 19,905 \\
\hline S09 & Injury, scalp & 1 & 21 & 452,088 & 269,083 & 721,171 \\
\hline $\mathrm{S} 13$ & Dislocat ion, strain, sprain: neck & 6 & 32 & 394,672 & 109,720 & 504,392 \\
\hline $\mathrm{S} 20$ & Minor injury, chest & 6 & 130 & $1,794,368$ & 683,295 & $2,477,663$ \\
\hline S22 & Fracture, ribs, chest, and back & 2 & 10 & 165,230 & 76,619 & 241,849 \\
\hline S23 & Dislocation, strain, sprain: chest joints & 1 & 6 & 78,594 & 22,733 & 101,327 \\
\hline S3 1 & Open wound, abdomen and pelvis & 1 & 12 & 147,384 & 42,303 & 189,687 \\
\hline S32 & Fracture, spine and pelvis & 7 & 130 & $2,261,050$ & $1,136,234$ & $3,397,284$ \\
\hline S33 & $\begin{array}{c}\text { Dislocation, strain, sprain: back and pelvic } \\
\text { joints }\end{array}$ & 36 & 839 & $9,966,571$ & $2,446,985$ & $12,413,556$ \\
\hline S40 & Minor wound, shoulder and arm & 12 & 129 & $1,705,848$ & 697,614 & $2,403,462$ \\
\hline S42 & Fracture, shoulder and arm & 3 & 17 & 284,043 & 163,179 & 447,222 \\
\hline $\mathrm{S} 43$ & Dislocation, strain, sprain: arm joints & 9 & 88 & $1,062,716$ & 286,409 & $1,349,125$ \\
\hline S50 & Minor wound, lower arm & 2 & 12 & 156,404 & 54,736 & 211,140 \\
\hline S52 & Fracture, lower arm & 3 & 34 & 651,624 & 320,816 & 972,440 \\
\hline S53 & Dislocation, strain, sprain: elbow joints & 2 & 22 & 297,924 & 92,364 & 390,288 \\
\hline S60 & Minor wound, wrist and hand & 6 & 30 & 378,682 & 135,393 & 514,075 \\
\hline S61 & Open wound, wrist and hand & 3 & 88 & $1,189,320$ & 431,938 & $1,621,258$ \\
\hline S62 & Fracture, wrist and hand & 8 & 59 & 998,480 & 454,374 & $1,452,854$ \\
\hline S63 & Strain, sprain: wrist and hand & 13 & 327 & $4,513,085$ & $1,544,895$ & $6,057,980$ \\
\hline S66 & Tendon/muscle injury, wrist and hand & 1 & 2 & 34,108 & 14,893 & 49,001 \\
\hline S70 & Minor injury, buttocks and femur area & 36 & 396 & $5,396,970$ & $2,118,193$ & $7,515,163$ \\
\hline S7 1 & Open wound, buttocks and femur areas & 1 & 8 & 108,168 & 36,129 & 144,297 \\
\hline S73 & Dislocation, strain, sprain: buttocks & 6 & 119 & $1,549,066$ & 486,008 & $2,035,074$ \\
\hline
\end{tabular}


Sang Gon Lee: Incidence and Estimation of Socioeconomic Costs Associated with

Falls among Elderly in Rural Areas of Korea

\begin{tabular}{lcccccc} 
S80 & Minor wound, lower leg & 25 & 194 & $2,528,513$ & 873,847 & $3,402,360$ \\
S81 & Open wound, lower leg & 10 & 130 & $1,729,402$ & 580,130 & $2,309,532$ \\
S82 & Fracture, ankle and lower leg & 18 & 368 & $6,596,148$ & $3,306,398$ & $9,902,546$ \\
S83 & Dislocation, strain, sprain: knee Joints & 48 & 645 & $8,247,024$ & $2,539,199$ & $10,786,223$ \\
S86 & Tendon/muscle injury, lower leg & 2 & 9 & 123,441 & 43,435 & 166,876 \\
S90 & Minor wound, ankle and foot & 21 & 201 & $2,564,093$ & 948,385 & $3,512,478$ \\
S91 & Open wound, ankle and leg & 4 & 96 & $1,208,766$ & 391,460 & $1,600,226$ \\
S92 & Fracture, foot except ankle & 13 & 172 & $3,139,823$ & $1,367,144$ & $4,506,967$ \\
S93 & Dislocation, strain, sprain: ankle & 15 & 172 & $3,037,577$ & 976,309 & $4,013,886$ \\
& Total & 324 & 4,503 & $62,835,799$ & $22,684,849$ & $85,520,648$ \\
\hline
\end{tabular}

ICD, International Classification Diseases; Won, Korean currency.

Table 4. Drug Costs of Patients and Analgesics of Health Functional foods Purch ase

\begin{tabular}{cccc}
\hline & $\begin{array}{c}\text { Expense per } \\
\text { days/times* (Won) }\end{array}$ & $\begin{array}{l}\text { Use no. of } \\
\text { days/times }\end{array}$ & Total(Won) \\
\hline Drug costs of inpatients & 37,951 & 2,958 days & $112,259,000$ \\
Drug costs of outpatients & 6,548 & 4,503 times & $29,486,000$ \\
Analgesics of health functional foods & & $3,705,000$ \\
Total & & $145,450,000$ \\
\hline
\end{tabular}

*Expenses include Drug costs of insurer and insured.

Won, Korean curren cy.

Table 5. Total Direct Costs of Study Subjects Who Experienced Falls

\begin{tabular}{cccc}
\hline & Benefit treatment amount & $\begin{array}{c}\text { Non-benefit treatment } \\
\text { amount }\end{array}$ & Total \\
\hline Medical costs of inpatients & $289,226,000$ & $57,783,000$ & $347,009,000$ \\
Medical costs of outpatients & $85,521,000$ & $5,592,000$ & $91,113,000$ \\
Drug total costs & $141,745,000$ & $3,705,000^{*}$ & $145,450,000$ \\
Oriental medical costs of outpatients & $12,044,000$ & 850,000 & $12,894,000$ \\
\hline Total & $528,536,000$ & $67,930,000$ & $596,466,000$ \\
\hline
\end{tabular}

Values are Won (Korean currency).

*Analgesics costs of health function foods.

Table 6. Costs of Productivity Loss of Patients, Nursing Caregivers and Visitors

\begin{tabular}{|c|c|c|}
\hline Division & Indicator & Total(Won) \\
\hline $\begin{array}{l}\text { Costs of } \\
\text { productivity loss }\end{array}$ & $\begin{array}{c}\text { Inpatients } \\
\text { Male }(\mathrm{n}=39) \text { : daily pay } 32,661 \text { (Won) } \times 1,347 \text { (day) }=43,994,367 \text { (Won) } \\
\text { Female }(\mathrm{n}=82) \text { : daily pay } 21,937 \text { (Won) } \times 1,611 \text { (day) }=35,340,507 \text { (Won) } \\
\text { Outpatients } \\
\text { Male }(\mathrm{n}=98) \text { : daily pay } 16,330 \text { (Won) } \times 1,273 \text { (day) }=20,788,090 \text { (Won) } \\
\text { Female }(\mathrm{n}=226 \text { ): daily pay } 10,969 \text { (Won }) \times 3,230 \text { (day) }=35,429,870 \text { (Won) }\end{array}$ & $135,553,000$ \\
\hline $\begin{array}{l}\text { Costs of Nursing } \\
\text { caregivers }\end{array}$ & $\begin{array}{l}\text { All days }(\mathrm{n}=56): 70,000(\text { Won }) \times 841(\text { day })=58,870,000(\text { Won }) \\
\text { Days }(\mathrm{n}=38): 35,000(\text { Won }) \times 372(\text { day })=13,020,000(\text { Won }) \\
\text { Nights }(n=10): 35,000(\text { Won }) \times 92(\text { day })=3,220,000(\text { Won })\end{array}$ & $75,110,000$ \\
\hline Costs of Visitors & $\begin{array}{c}\text { Times } \\
1,418 \text { (times) } \times \text { daily pay } 90,733 \text { (Won) } \times 50 / 100=64,329,697 \text { (Won) }\end{array}$ & $64,330,000$ \\
\hline Total & & $274,993,000$ \\
\hline
\end{tabular}

Won, Korean currency. 
Table 7. Socioeconomic Costs associated with Falls among the Elderly in Rural Communities in This Study

\begin{tabular}{lcc}
\hline Division & Categories & Cost \\
\hline Direct costs & Benefit treatment amount & $528,536,000(50.12)$ \\
& Non-benefit treatment amount & $67,930,000(6.44)$ \\
Indirect costs & Subtotal & $596,466,000(56.56)$ \\
& Nursing caregivers & $48,755,000(4.62)$ \\
& Diaper purchase & $312,000(0.03)$ \\
& Transportation costs & $43,122,000(4.09)$ \\
& Health functional foods Purchase & $65,531,000(6.21)$ \\
& Accessory product Purchase & $25,368,000(2.41)$ \\
& Costs of productivity loss & $274,993,000(26.08)$ \\
& Subtotal & $458,081,000(43.44)$ \\
\hline
\end{tabular}

Values are presented as Won (\%). Won, Korean currency.

Table 8. Socioeconomic Costs associated with Falls among Elderly in Rural Communit ies in Korea2009

\begin{tabular}{cccc}
\hline \multirow{2}{*}{ Division } & Categories & \multicolumn{2}{c}{ Cost (Won) } \\
\cline { 3 - 4 } Direct & Benefit treatment amount & Elderly $(\mathrm{n}=2,295)^{*}$ & Elderly $(\mathrm{n}=1,067,262) \dagger$ \\
\hline \multirow{2}{*}{$\begin{array}{c}\text { costs } \\
\text { Indirect }\end{array}$} & Non-benefit treatment amount & $528,536,000$ & $169,408,506,000$ \\
costs & Subtotal & $67,930,000$ & $21,773,431,000$ \\
& Nursing caregivers & $596,466,000$ & $191,181,937,000$ \\
& Diaper purchase & $48,755,000$ & $21,234,266,000$ \\
& Transportation costs & 312,000 & $100,004,000$ \\
& Health functional foods Purchase & $43,122,000$ & $13,821,528,000$ \\
& Accessory Product Purchase & $65,531,000$ & $21,004,321,000$ \\
Total & Costs of productivity loss & $25,368,000$ & $8,131,097,000$ \\
& Subtotal & $274,993,000$ & $88,141,835,000$ \\
& & $458,081,000$ & $152,433,051,000$ \\
& & $1,054,547,000$ & $343,614,988,000$ \\
\hline
\end{tabular}

*Elderly persons 65 years or older living in rural communities (1 township and 1 village of Gyoengsangnam-do), †Elderly persons 65 years or older living in rural communit ies.

Won, Korean currency.

\subsection{Estimation of Socio-Economic Cost associated with Falls among Edderly in Rural Regional Communities}

\subsubsection{Socio-economic Cost associated with the Fall Injuries} of the Subjects of This Study

As a result of this study, of the 2,295 elderly of rural regions who were study subjects, the total socio-economic cost associated with falls of the 735 elderly who experienced a fall in the past year was calcu lated to be 1,054,547,000 won, in which the per person average cost for the entire study subject elderly was 459,500 won and the per person average cost of the elderly who experienced a fall was $1,435,000$ won. Of the socio-economic cost, the direct cost was seen to be $56.56 \%$ and the indirect cost was seen to be $43.44 \%$; of the direct cost, the insured portion was $50.12 \%$, uninsured portion was $6.44 \%$ and, of the ind irect cost, the loss of productivity was $26.08 \%$, health food purchase was $6.21 \%$, nurs ing care cost was $4.62 \%$, transportation cost was $4.09 \%$, accessory product purchase cost was $2.41 \%$, and diaper purchase cost was $0.03 \%$ (Table 7 ).

\subsubsection{Estimation of the Socio-economic Cost associated with Fall Injuries of the Elderly of Korea}

The total socio-economic cost as sociated with falls of the 735 elderly among the 2,295 elderly of some rural regions who experienced a fall in the past year was calculated to be $1,054,547,000$ won, which resulted in the per person average cost of an elderly person who experienced a fall being 
$1,435,000$ won. As such, by applying the socio-economic cost associated with falls in some rural reg ional co mmunities calculated in this study to the 2009 elderly population figure in Korea of $1,067,262$, while taking into consideration the gender and the municipality and province-wise population of rural elderly population, the incidence of elderly falls were compensated and calculated afterwards, which resulted in an annual socio-economic cost of 343.6 billion won that can be incurred due to the elderly in the rural regions of Korea who experienced falls (Table 8).

\section{Discussion}

Of the 2,295 study subjects of this study, $32.0 \%$ of the elderly experienced a fall in the past year, which was almost the same level co mpared to the $30.0 \%$ incidence of falls seen in the advanced Western countries[15].It was observed that the percentage of elderly who experienced 1 fall was $12.3 \%$ and the elderly who experienced rather frequent falls (more than 2)was $19.7 \%$; co mpared to the $15 \%$ seen for the elderly with frequent falls mentioned in the study by Stolze and colleagues [16], this study showed a slightly higher level. The risk of an accident is higher for the elderly who experience frequent falls, and Cho and Yoon[6] stated that elderly who have had more than 2 experiences of a fall have a higher frequency of falls, as their intrinsic risk and extrinsic risk factors occur in combination. Due to this, the severity of the injury worsens, causing the degradation of quality of life for the elderly and resulting in the possible increase of socio-economic costs. In regard to the injury areas, the knees were the highest with $31.2 \%$, wh ich at first did not appear to be an injury, but later manifested as an injury (28.0\%), followed by abrasion wounds with $24.9 \%$, sprains and strains with $24.5 \%$, and fractures with $14.1 \%$. The findings by Kim[8]showed that lower limbs were the highest with $30.2 \%$ in terms of the injury area, and the study by Ham[13]showed that physical injury was highest in the lower limbs at $31.1 \%$, both of which appeared to be similar to the results of this study. The injury types in the study by Kim[8]showed that fractures and contusions were the highest at $24.2 \%$ each, with Ham's[13]study showing bruises at $46.3 \%$ followed by fractures at $24.5 \%$. In comparing these findings with the results of this study, in falls among the elderly (in terms of injury areas), injuries to the knee seem to occur the most, and, in terms of injury types(albeit existing differences among researchers), there are many cases of no injury from falls; when injuries do occur, it can be asserted that they occur in the forms of abrasion wounds, sprains and strains, fractures, etc. Of the 735 elderly who experienced a fall, $16.5 \%$ of them were ad mitted to the hospital, $44.1 \%$ of them used outpatient services, and, of the elderly who were hospitalized, the cases of fractures were the most common with $63.6 \%$. Kim[8]showed that those who responded as saying they were hospitalized due to a fall were $33.3 \%$; Kim[14] showed this number to be 5.7\%; and Tinetti, Speechley, and Ginter[15] stated that $10 \%$ of the elderly who experienced a fall required medical treatment, $5 \%$ of them experienced fractures, and $2.5 \%$ of them required hospitalization due to fracture. In comparing these findings with the results of this study, the cases of the elderly who were admitted to the hospital were seen to be higher than the results of studies that were conducted abroad. Also, with the results of domestic studies, this study showed significant differences, which may attributable to the fact that the domestic studies by Kim[8] and by Kim[14]only identified, in accordance with the injury types, whether or not the elderly were hospitalized but not if they used outpatient services. The study of Tinetti, Speechley, and Ginter[15] is limited due to its statement that hospitalization was required only for fractures. This is because, despite the fact that not only due to fracture but also to external injuries (such as sprains and strains, long-term injuries, dislocations, open wounds, etc.), a patient could have been admitted to the hospital, but the study did not investigate this possibility properly. Of the 735 persons who experienced a fall, 260 elderly patients $(35.4 \%)$ received Oriental outpatient treatment, and there were no patient subjects who received dental care. In both domestic studies and studies abroad there were no investigations on whether or not Oriental medicine treatment or dental care was sought by elderly fall patients, and as a result, comparisons could not be made. Despite this, there are currently many patients who are receiving Oriental medicine treatment in cases of damage to parts of the body due to a fall; therefore, it is deemed that further studies in this field are warranted. Those who purchased accessory products after a fall were found to be $14.4 \%$. As such, it is deemed necessary to produce and distribute accessory products that are easy to use and aesthetically pleasing to the elderly. In particular, considering that Long Term Care Insurance coverage started on July 1, 2008,covering items such as wheelchairs, walkers, canes, and walking assistants, providing these easy to use and highly useful items would not only as sist the elderly who experience a fall, but also those with dementia, since the fall occurrence rate is particularly higher in elderly patients with dementia. Of the elderly who experienced a fall, 468 persons (63.7\%) purchased health functional food: the elderly who purchased "pas," or pain-re lieving patches, were the highest at $33.7 \%$, fo llowed by analgesics at $23.5 \%$, health functional food for jo ints at $13.9 \%$, and calcium supplements at $10.6 \%$, thereby indicating that many elderly people purchase health supplements after a fall. In the study by Jung, Lee, and Jung[9]there were significant differences between whether or not health functional food was taken after experiencing a fall, and it was observed that $56.6 \%$ of the group of elderly who experienced a fall were using health functional foods. A number of elderly people are known to be using glucosamine and chondroitin sulfate, which are recognized as health functional foods for the joints and foods that relieve joint pain and promote cartilage growth while preventing wear and loss; however, the effectiveness of these have not been proven, and this kind of purchasing behavior is deemed to be furthering the economic burden on the elderly who purchase these expensive health functional foods. In general, the types 
of cost of a disease are classified as tangible cost and intangible cost, and the tangible cost can be further classified as direct cost and indirect cost. The direct cost refers to the expended cost for hospitalization, outpatient visits, medication, screening, and others for the purposes of disease prevention and treatment, emergency medical treatment, research, and even the costs of education. The indirect cost usually includes the cost of transportation and cost of time for gaining access to health care providers and the loss of productivity from work reduction, interruption, or other factors[17-18]. As a domestic study of socio-economic cost related to diseases, the study by Lee[19]estimated the socio-economic cost due to diseases in Korea and the results showed that the total cost was 36.87 trillionwon; of the med ical treatment cost, the per capita cost of persons in their 60 s and 70 s covered by insurance was seen to be from 574,000 won to 746,000 won. $\operatorname{Kim}[20]$ estimated that the socio-economic cost associated with stroke in Korea to be 3.737 trillion won, where the per-stroke patient socio-economic costs was 2,686,000 won. Kang and colleagues[5]estimated in their analysis of the reality of the socio-economic costs associated with dementia, based on a survey of 609 participants, that a socio-economic cost of 4.79 billion won was incurred, and, per dementia patient, 5,070,000 won in direct cost and 2.8 million won in indirect cost were used. According to a study done outside Korea on the socio-economic cost associated with falls, according to the study of Englander, Hodson, and Terregrossa[21], \$64.04 billion was the resulting socio-economic costs that could have incurred looking at the total U.S. population in 1995; the actual direct cost expended due to falls among elderly was $\$ 20.01$ billion, or $\$ 7,399$ average per person. In addition, in 2020 , the cost that can be incurred due to falls among elderly is forecast to increase by $55 \%$ to $\$ 31.04$ billion. In this study, the socio-economic cost associated with falls in some rural regional communities was compensated, while taking into consideration the regional aspects of the incidence of elderly falls, to the 2009 figure of the elderly population of Korea as $1,067,262$ [22], and the estimated result was calculated to be 343.6 billion won. In comparing the estimated figures of the socio-economic costs that could be incurred by diseases, dementia, strokes, and falls, falls are deemed to have higher socio-economic costs that could be incurred than that of diseases, and lower than the socio-economic cost of dementia or strokes. In addition, the total socio-economic cost associated with falls among the elderly in the rural areas of Korea is 343.6 billion won, which is $0.9 \%$ of the socio-economic cost attributable to diseases and $9.2 \%$ of the socio-economic cost attributable to strokes. However, when taking into consideration the total elderly population, it is analyzed that very significant costs would be incurred. In the analysis of socio-economic cost related to falls, the data from Korea National Health Insurance can be used for calculating med ical treatment cost (which is a direct cost); however, due mainly to the fact that the classification system for injury related monitoring is still lacking in Korea, and the reality that the data is not useable, there is little choice but to rely only on questionnaire-based surveys for estimating costs (including the indirect costs). In comparison of the results of this study to the studies done outside of Korea on the socio-economic cost associated with falls, the study of Englander, Hodson, and Terregrossa[21] used data from the U.S. Department of Health Bureau of Statistics and calculated direct costs (medical treatment cost, nursing care cost, drug cost, medical equip ment purchase cost, insurance cost, vocational rehabilitation cost, etc.) and indirect costs (cost of productivity loss and income loss due to premature death)for their analysis of the socio-economic cost associated with falls by applying estimation methods; the study of this paper estimated the socio-economic cost using a survey questionnaire as the basis and excluded the income loss of elderly attributable to premature deaths. This was due to the fact that cases of elderly people dying from a fall are rare. Taking into consideration the fact that, in overseas studies, of the $\$ 7,399$ average per person fall related cost of the elderly, the direct cost was $\$ 6,215(85.0 \%)$, productivity loss was $\$ 1,145(15.5 \%)$, and the income loss due to premature deaths was $\$ 39(0.5 \%)$, i.e., the premature death-related income loss was too small relatively; therefore, this was not included in the estimation of costs. Although there may be differences in terms of the comprising items of direct cost and indirect cost among researchers in estimating the socio-economic costs associated with diseases and injuries, if the comprising items of this study (except for the loss of productivity) were to be considered as direct costs, then direct costs would be $74 \%$ and indirect costs would be $26 \%$, showing similar ratios of direct and indirect costs of those of overseas studies. Although this study has some limitations as to its representativeness, due in part to only using the elderly in so me rural regions as subjects as well as possible shortcomings in estimation methods, it can be asserted that the significance of this study may come from the fact that, despite the elderly population being on a rapid increase and falls among elderly being a serious health issue, studies on estimating the associated socio-economic costs are lacking. For a precise estimation, the appro ximate direct and indirect costs based on representative samples are required, including surveys that target the entire nation (such as the national health and nutrition examination survey or regional co mmun ity health survey); specific surveys of items for estimating the socio-economic cost associated with falls among elderly are therefore warranted. Based on the results thusfar, falls among elderly are a serious element of health threats. Therefore, moving forward, it is necessary that a system that establishes and evaluates the preventive policies and measures for elderly injuries from an overall perspective at a national level is established as the elderly population continues to increase, which certainly would entail increases in the elderly who experience falls and the accompanying socio-economic cost burden.

\section{Conclusions}


In order to estimate the socio-economic cost associated with falls among that elderly that could be incurred, a census was conducted on 2,295 persons aged 65-years or older, who resided in Guemnam township in the Hadong county of Gyeongsangnam-do Province and Sancheong village of Sanchcheong county. During the study period that lasted from February 1, 2010 to March 31, 2010,the following was also investigated: the $32.0 \%$ incidence of falls in the past year (of which $61.5 \%$ experienced more than 2 falls), and the elderly experienced in falls were found to be, as the frequency of falls increased, exacerbating the economic burden of the elderly who are poor. Attributable to the 735 persons who experienced falls, it was found that the total socio-economic cost arising from injuries due to falls was $1,054,547,000$ won. Based on these results, the regional fall incidence were compensated with respect to the elderly population of 1,067,262 in 2009 in the rural regions of Korea, and the socio-economic cost associated with falls was roughly estimated, resulting in an approximate total cost of $343,614,988,000$ won. When taking into consideration that the urban elderly population, which is $20 \%$ of the total elderly population, and also that the width of increase in elderly population is accelerating, the socio-economic cost is expected to increase significantly and it is deemed that the establishment of policies for and research on the prevention of injuries for the elderly population for reducing the socio-economic cost need to proceed.

\section{REFERENCES}

[1] Korean Geriatrics Society, Textbook of geriatric medicine. 2nd ed. Seoul: Medical Publishing Co,2000. p. 329-339

[2] Cho, J.P., et al., Prevalence and associated factors of falls in the elderly community. Korean J PrevMed, 2001.34:p. 47-54

[3] Grisso, J.A., et al., Risk factors for falls as a cause of hip frac-ture in women: The Northeast Hip Fracture Study Group. N Engl J Med, 1991.324:p. 1326-1331

[4] Sattin, R.W., Falls among older persons: a public health pers-pective. Annu Rev Public Health, 1992.13:p. 489-508

[5] Kang, H.O., et al., The socioeconomic costs associated with dementia patients. Seoul: National Health Insurance, 2005

[6] Cho, Y.C., and Yoon, H.S., Falls among community elderly people: prevalence and associated factors. Korean J Rural Med, 2004.29:p. 223-35

[7] Park, M.H., and Song, K.A., Risk factors of stroke patients falling in geriatric hospital. J KoreanGerontololNurs, 2005.7:p. 104-13

[8] Kim, D.J., Prevalence and associated factors of falls in the elderly in a rural community.[dissertation]. Seoul: Seoul National University, 2002

[9] Jung, Y.M., Lee, S.E., and Jung, K.S., Prevalence and associated factors of falls according to health status in elderly living in the community. J Korea GerontololSoc, 2006.26:p.
291-303

[10] Lim, N.G., et al., A study on the prevalence and associated factors of falls in some rural elderly. J Korean GeriatrSoc, 2002.6: p. 183-196

[11] Lim, J.Y., et al., Falls in a proportional region population in Korean elderly: incidence, consequences, and risk factors. J Ko-reanGeriatrSoc, 2010.14: p. 8-17

[12] Lee, E.J., and Kim, C.G., A survey of fracture and factor asso-ciated with falls in elderly patients. J Korean GerontololNurs, 2003.5: p. 182-192

[13] Ham, S.H., A study on analysis of health status and risk fac-tors of injury in rural elderly.[dissertation]. School: Seoul National University, 2003

[14] Kim, M.J., A associated factors caused by falls of older people in community-dwelling.[dissertation]. Seoul: Ewha Women University, 2004

[15] Tinetti, M.E., Speechley, M., and Ginter, S.F., Risk factors for falls among elderly persons living in the community. $\mathrm{N}$ Engl J Med, 1988.319: p. 1701-1707

[16] Lim, J.Y., et al., Falls in a proportional region population in Korean elderly: incidence, consequences, and risk factors. J Ko-reanGeriatrSoc, 2010.14: p. 8-17

[17] Kim, M.J., A associated factors caused by falls of older people in community-dwelling.[dissertation]. Seoul: Ewha Women University, 2004

[18] Tinetti, M.E., Speechley, M., and Ginter, S.F., Risk factors for falls among elderly persons living in the community. $\mathrm{N}$ Engl J Med, 1988.319: p. 1701-1707

[19] Lim, J.Y., et al., Falls in a proportional region population in Korean elderly: incidence, consequences, and risk factors. J Ko-reanGeriatrSoc, 2010.14: p. 8-17

[20] Lee, E.J., and Kim, C.G., A survey of fracture and factor asso-ciated with falls in elderly patients. J Korean GerontololNurs, 2003.5: p. 182-192

[21] Ham, S.H., A study on analysis of health status and risk fac-tors of injury in rural elderly.[dissertation]. School: Seoul National University, 2003

[22] Kim, M.J., A associated factors caused by falls of older people in community-dwelling.[dissertation]. Seoul: Ewha Women University, 2004

[23] Tinetti, M.E., Speechley, M., and Ginter, S.F., Risk factors for falls among elderly persons living in the community. $\mathrm{N}$ Engl J Med, 1988.319: p. 1701-1707

[24] Stolze, H., et al., Falls in frequent neurological diseases: prevalence, risk factors and etiology. J Neurol, 2004.251: p. $79-84$

[25] Rice, D.P., Cost of illness studies: what is good about them? InjPrev , 2000.6: p. 177-179

[26] Rice, D.P., and MacKenzie, E.J., Cost of Injury in the United States: A Report to Congress. San Francisco: Institute for Health \& Aging, University of California and Injury Prevention Center, The Johns Hopkins University, 1989

[27] Lee, S.M., Socioeconomic costs of disease and alcohol drink-ing in Korea.[dissertation]. Seoul: Yonsei University, 
2007

[28] Kim, S.M., A study on the caregiver's burden of senile de-mentia and stroke patients.[dissertation]. Yongin: DankookUni-versity, 2004

[29] Englander, F., Hodson, T.J., and Terregrossa, R.A.,
Economic dimensions of slip and fall injuries. J Forensic Sci, 1996.41: p. 733-746

[30] A ages and sex of farmhouse population[Internet]. Daejeon: Statistics Korea; c1996. [cited 2010 Aug 20]. Available from: http://kostat.go.kr/portal/index/statistics.action. 